\title{
A miniature Marine Aerosol Reference Tank (miniMART) as a compact breaking wave analogue
}

\author{
M. Dale Stokes ${ }^{1}$, Grant Deane ${ }^{1}$, Douglas B. Collins ${ }^{2}$, Christopher Cappa $^{3}$, Timothy Bertram ${ }^{4}$, Abigail Dommer ${ }^{1}$, \\ Steven Schill $^{4}$, Sara Forestieri ${ }^{3}$, and Mathew Survilo ${ }^{3}$ \\ ${ }^{1}$ Marine Physical Laboratory, Scripps Institution of Oceanography, La Jolla, CA, USA \\ ${ }^{2}$ Dept. of Chemistry, University of Toronto, Ontario, Canada \\ ${ }^{3}$ Dept. of Civil and Environmental Engineering, University of California, Davis, CA, USA \\ ${ }^{4}$ Dept. of Chemistry, University of Wisconsin, Madison, WI, USA \\ Correspondence to: M. Dale Stokes (dstokes@ucsd.edu)
}

Received: 27 April 2016 - Published in Atmos. Meas. Tech. Discuss.: 19 May 2016

Revised: 19 July 2016 - Accepted: 8 August 2016 - Published: 1 September 2016

\begin{abstract}
In order to understand the processes governing the production of marine aerosols, repeatable, controlled methods for their generation are required. A new system, the miniature Marine Aerosol Reference Tank (miniMART), has been designed after the success of the original MART system, to approximate a small oceanic spilling breaker by producing an evolving bubble plume and surface foam patch. The smaller tank utilizes an intermittently plunging jet of water produced by a rotating water wheel, into an approximately $6 \mathrm{~L}$ reservoir to simulate bubble plume and foam formation and generate aerosols. This system produces bubble plumes characteristic of small whitecaps without the large external pump inherent in the original MART design. Without the pump it is possible to easily culture delicate planktonic and microbial communities in the bulk water during experiments while continuously producing aerosols for study. However, due to the reduced volume and smaller plunging jet, the absolute numbers of particles generated are approximately an order of magnitude less than in the original MART design.
\end{abstract}

\section{Introduction}

Sea spray aerosols (SSAs) are generated over a large portion of the Earth's surface and form a large fraction of aerosol particulates present in the atmosphere (e.g., Lewis and Schwartz, 2004). They are critically important components in global biogeochemical cycles (e.g., Solomon et al., 2007) and important modifiers of atmospheric radiative bud- gets. Marine aerosols are generated primarily by processes associated with the formation of bubble plumes and foams generated by the actions of breaking surface waves. Breaking waves themselves play an important role in many additional processes at the air-sea interface including mixing, current formation, heat and momentum flux, and the bubbles entrained by breaking waves enhance gas transport, scavenge biological surfactants, and generate ambient noise in addition to creating aerosol particles (e.g., Woodcock, 1953; Wallace and Duce, 1978; Rapp and Melville, 1990; Tseng et al., 1992).

Oceanic whitecaps (which are the high optical albedo footprint of a breaking surface wave) typically form once wind speeds greater than approximately $3 \mathrm{~ms}^{-1}$ blow over a sea surface of sufficient fetch. Breaking itself includes the impaction of the overturning wave crest with the sea surface and subsequent entrainment and fragmentation of air into a plume of bubbles. The plume evolves over a timescale of seconds to a few tens of seconds due to buoyancy and turbulent flow forces acting on the entrained bubbles. The air/water mixture of the breaking wave crest and the bubbles that reach the sea surface after breaking form the high albedo patch characteristic of a whitecap. Surface bubbles and the dense aggregations of bubbles that create surface foams are the primary source of marine aerosols as the bubbles rupture and produce a spray of jet and fluid film droplets that are ejected into the atmosphere (Lewis and Schwartz, 2004).

In order to study marine aerosol production it is beneficial to have a standardized method of creating them that mimics 
the formation processes associated with marine foam in repeatable, controlled conditions in the laboratory. Several different methods have been used to generate surrogate marine aerosols within enclosed tanks including pressurized atomizers (Svenningsson et al., 2006; Riziq et al., 2007; Saul et al., 2006; McNeill et al., 2006; Braban et al., 2007; Niedermeier et al., 2008; Taketani et al., 2009), forcing air through glass filters or sintered materials (Cloke et al., 1991; Martensson et al., 2003; Sellegri et al., 2006; Keene et al., 2007; Tyree et al., 2007; Wise et al., 2009; Hultin et al., 2010; Fuentes et al., 2010) and by a plunging water jet (Cipriano and Blanchard, 1981; Sellegri et al., 2006; Facchini et al., 2008; Fuentes et al., 2010). The detailed investigations by Sellegri et al. (2006) and Fuentes et al. (2010) have shown that the best method for the generation of proxy marine aerosols is by creating a bubble plume from a plunging jet of water. In addition Collins et al. (2014) have shown that the method of bubble production influences the chemical composition of laboratory-generated sea spray aerosol, with a plunging water method showing better agreement with aerosol produced from laboratory breaking waves than did aerosol generated via the sintered glass filter method. The plunging jet apparatus used by Fuentes et al. (2010) used a relatively small volume of water $(6 \mathrm{~L})$ in an $11 \mathrm{~L}$ tank filled to a depth of $11 \mathrm{~cm}$. Using a modification of the prior plunging water techniques, Stokes et al. (2013) developed the Marine Aerosol Reference Tank (MART) system that accurately reproduced the bubble plumes and marine aerosols characteristic of an oceanic whitecap. By using an intermittent plunging sheet of water in a larger $(210 \mathrm{~L})$ tank bubble plumes are formed that mimic the oceanic bubble size distribution, including critical bubbles larger than the Hinze scale (the transition point between bubbles stabilized by surface tension and bubbles subject to fragmentation by turbulence at approximately $1 \mathrm{~mm}$ scale), and have a temporal evolution similar to plumes measured in the ocean and in large laboratory wave tanks.

\section{Whitecap foam and bubble size distributions}

The two primary production mechanisms of sea spray aerosols at moderate wind speeds are the disintegration of the thin fluid films associated with whitecap foam (film drops) and the breakup of the jet of water formed at the base of a bubble shortly after the rupture of its film (jet drops). Both of these mechanisms are known to be sensitive to bubble size. It follows that an essential requirement of any laboratory system designed to produce nascent SSA is the reproduction of the numbers and sizes of bubbles entrained by breaking waves in the open ocean. Few bubble size distributions from natural breaking waves have been acquired because of the difficulty of making measurements in stormy conditions and other natural hazards (Herrero, 1985; Melville, 1996; de Leeuw and Cohen, 2002; Stokes et al., 2002). However, some oceanic measurements are available as well as a num-

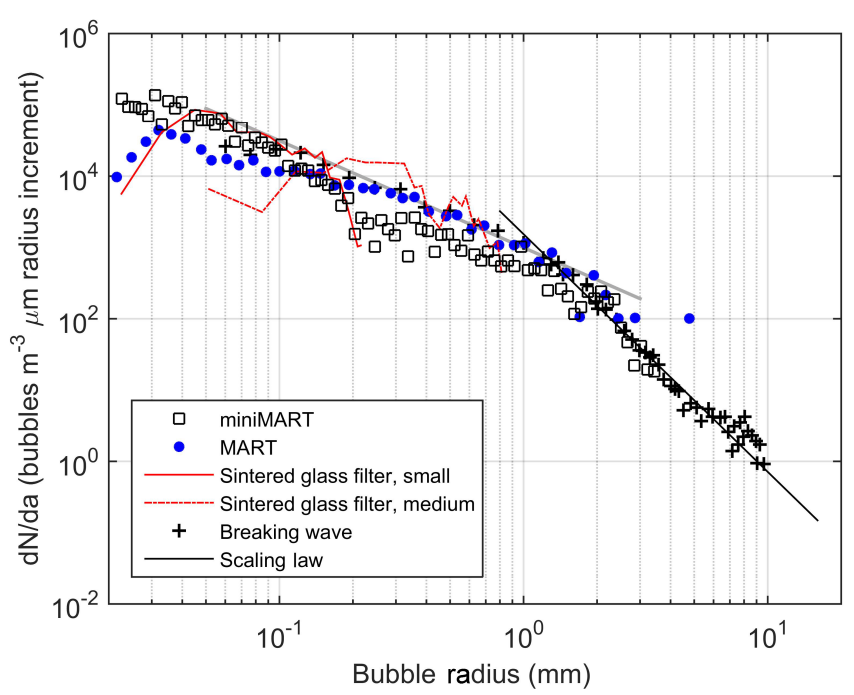

Figure 1. Inter-comparison of bubble size distributions from a laboratory breaking wave, the plunging jet in the miniMART system, the original MART system, and two distributions from sintered glass filters. The breaking wave distribution is in absolute units; the MART and sintered glass filter bubble distributions have been scaled as described in the text. The sloped solid lines indicate size distribution scaling laws as measured from oceanic bubble plumes showing the change in slope at the bubble Hinze scale (where the lines intersect). Additional information on the size distributions can be found in Stokes et al. (2013).

ber of laboratory studies (e.g., Monahan and Zeitlow, 1969; Cipiriano and Blanchard, 1981; Bezzabotnov et al., 1986; Lamarre and Melville, 1994; Loewen et al., 1995; Leighton et al., 1996; Deane and Stokes, 2002; de Leeuw and Cohen, 2002; de Leeuw and Leifer, 2002; Leifer and de Leeuw, 2002, 2006; Stokes et al., 2002) and are summarized in Fig. 1 of Stokes et al. (2013). It is now known that there is a scale dependence to the bubble creation physics, differentiated by a length scale known as the Hinze scale (Deane and Stokes, 2002). The Hinze scale $\left(a_{\mathrm{H}}\right)$ defines the radius of a bubble for which surface tension forces, which tend to keep bubbles spherical, are disrupted by distorting pressure fluctuations associated with fluid turbulence. This scale is of the order of $1 \mathrm{~mm}$ in spilling and breaking waves. Bubbles smaller than the Hinze scale are stabilized to fragmentation by fluid turbulence, whereas bubbles larger than this scale are subject to a turbulent fragmentation cascade.

The power law dependence of the bubble size distribution as a function of bubble radius is also different for bubbles smaller and larger than the Hinze scale. Smaller bubbles have a somewhat variable power law scaling, $a^{-n}$ with $n$ taking values between approximately 1 to 2 . The physics of bubble fragmentation and bubble degassing drives a steeper power law dependence for bubbles larger than the Hinze scale with $n$ taking values between approximately 3 to 4 (Fig. 1). Important points are that (1) breaking oceanic whitecaps can 
produce large bubbles, greater than $1 \mathrm{~mm}$ radius and up to $4 \mathrm{~mm}$ radius (Bowyer, 2001), and (2) the power law scaling of the generation of these bubbles is controlled by fluid turbulence within the whitecap and differentiated by the Hinze scale. In order to accurately reproduce nascent SSA, the laboratory bubble generation mechanism needs to produce bubbles larger than the Hinze scale and reproduce the power law dependence those bubbles acquire through fragmentation in fluid turbulence.

\section{The miniature Marine Aerosol Reference Tank (miniMART)}

The original MART system was constructed to closely mimic the bubble plume, foam, and aerosol generating mechanisms active during oceanic wave breaking and to provide a portable, controllable environment in which to explore and sample these processes (Stokes et al., 2013). The primary design of MART included a flow-controlled closed-loop circulation system that draws water from the tank bottom, a tanktop spillway or waterfall to produce a plunging sheet that impacts the water surface within the tank to produce a bubble plume, and an air-tight headspace for controlled aerosol sampling while the system is operating. By varying the temperature of the tank contents, the water chemistry and the characteristics of the plunging sheet (volume, angle and distance of drop, timing of the intermittency) a wide range of experimental conditions can be realized. The tank itself can also be used as an incubator for the growth of planktonic organisms to investigate the influence of biogenic exudates on SSA formation (Lee et al., 2015). A limitation with the MART system is that it can be difficult to culture delicate organisms in the reservoir while the external circulation pump (1/3 HP centrifugal pump) is operational because the high flow rates $\left(70 \mathrm{~L} \mathrm{~min}^{-1}\right.$ within the pump casing and up to $15 \mathrm{~L} \mathrm{~min}^{-1}$ in the waterfall flow) create high levels of fluid shear that is damaging to fragile cells. Hence, when including cultured cells in the experimental system it is necessary to limit pump cycling (and aerosol generation) to after the culture has reached its exponential growth phase or reached a cell density where losses due to pump cycling do not exceed cell creation rates.

The miniMART system (Fig. 2) described here was designed to provide a gentle method of plunging jet generation that would minimize destructive shear on cultured organisms and still permit the continuous generation of aerosols for study. It was fabricated using components that are readily available and constructed of stainless steel, Plexiglas and silicone wherever possible to minimize chemical contaminants and facilitate cleaning. The main tank $(25 \times 25 \times 30 \mathrm{~cm}, 19 \mathrm{~L}$ total volume) was made from $1.5 \mathrm{~cm}$ thick Plexiglas with an O-ring sealed, $20 \mathrm{~mm}$ thick Plexiglas lid to provide airtight integrity. Separate ports are available for sampling both the atmospheric headspace and subsurface water in the tank. Port

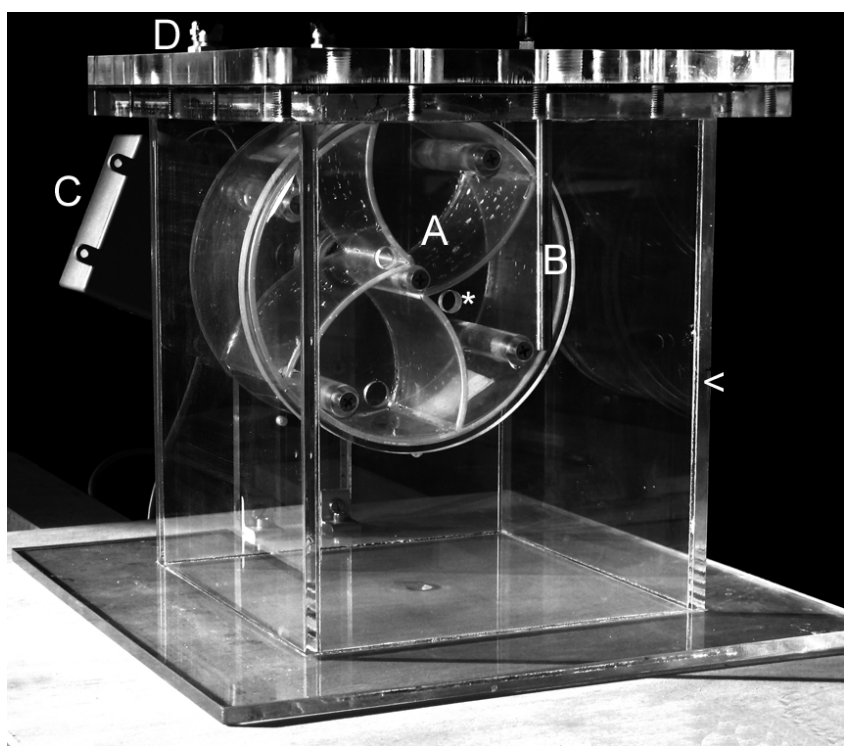

Figure 2. Image of miniature Marine Aerosol Reference Tank (miniMART $)$. The primary tank $(25 \times 25 \times 30 \mathrm{~cm}, 19 \mathrm{~L}$ total volume $)$ is made from $1.5 \mathrm{~cm}$ thick Plexiglas with an O-ring sealed, $20 \mathrm{~mm}$ thick Plexiglas lid. The intermittent plunging jet ( $70 \mathrm{~mL}$ volume) is formed by water escaping from alternating chambers in a rotating water wheel ( $20 \mathrm{~cm}$ diameter, $8 \mathrm{~cm}$ wide) labeled (a) and powered by an external, 8 RPM motor (c) connected to the wheel by a sealed shaft. An exit port on the wheel (indicated by the white star) allows the water to fall approximately $10 \mathrm{~cm}$ from the wheel to the water surface. The tank is filled with approximately $6 \mathrm{~L}$ of water to the water fill line indicated by the arrowhead $(<)$. A vertical stainless steel aerosol sampling tube (b) penetrates the tank lid for sampling near the water surface. Additional ports are located in the lid (d) for gas input and water sampling.

sampling tubes are made from stainless steel and positioned within $1 \mathrm{~cm}$ of the water surface to minimize the effects of particle losses to the Plexiglas tank walls.

Inside the tank, a $20 \mathrm{~cm}$ diameter, $8 \mathrm{~cm}$ deep, compartmentalized water wheel, and fabricated after an ancient sakia design, is rotated at approximately 8 RPM by an externally mounted $1 / 15$ HP motor attached to a shaft-sealed axle that penetrates the tank rear wall. A thin silicone gasket was used to seal the compartmentalized wheel to its removable lid, providing access to its internal surfaces for cleaning. The contact between the silicone and the water is minimized to a hairline gap between the lid and wheel once assembled, to mitigate potential effects of the silicone on water surface microlayer chemistry. The two internal chambers of the wheel provide the intermittent release of a $70 \mathrm{~mL}$ water jet from approximately $10 \mathrm{~cm}$ above the water surface within the tank (when filled with approximately $6 \mathrm{~L}$ of water) via a hole in the chamber wall. The plunging jet sweeps across the water surface when a chamber crosses the apex of its rotation (maximum height above the water surface) while the opposite chamber is synchronously filling beneath the water sur- 
face. The plunging jet impacts the water surface and produces a bubble plume that mimics the plunging jet of water from a breaking wave crest without the need for a powerful external pump. The small size of the miniMART system allows it to be partially submerged (to the water fill line) in a temperature-controlled bath allowing stabilization of its internal temperature if necessary for plankton culture growth. Alternatively, the miniMART can be operated in a temperature-controlled incubator or room, a technique that has proven viable even for the much larger MART system.

Before experimentation the miniMART system is cleaned to minimize contamination. The internal surfaces are scrubbed with $100 \%$ percent isopropanol and then the entire system is filled and the sakia wheel circulated with a $10 \%$ isopropanol/deionized water solution for approximately $30 \mathrm{~min}$. After circulation the tank is drained and then rinsed and filled with deionized water, and the system again circulated. Lastly, the system is flushed with filtered freshwater or seawater for experimentation. The system is considered clean when measurements of surface tension from water samples are the same as those from the filtered water supply used for experimentation (approximately $72 \mathrm{mNm}^{-1}$ at room temperature measured using the Wilhelmy plate method with a Krüss K3 tensiometer.)

\subsection{Bubble size distribution measurements}

To examine the utility of the miniMART system compared to the original MART and as an oceanic bubble plume proxy, the size distributions of bubbles within miniMART were compared to those produced by sintered glass filters as well as to oceanic and laboratory wave channel distributions. The glass filters were set at a depth of $\sim 25 \mathrm{~cm}$ (filter surface to water surface), and dry nitrogen gas $\left(0.5 \mathrm{~L} \mathrm{~min}^{-1}\right)$ was pumped through four filters, two $90 \mathrm{~mm}$ diameter type $\mathrm{E}$ filters and two $25 \mathrm{~mm}$ diameter type A filters, similar to the setup of Keene et al. (2007). A further description can be found in Stokes et al. (2013).

The sintered glass filter and plunging sheet bubble size distributions were obtained utilizing methods described previously by Deane and Stokes (2002). In brief, bubble plumes were imaged a few centimeters from the side of the tank using a Nikon high-resolution digital camera (Fig. 3). The distribution of bubble sizes was then obtained through computer-aided analysis of the images. The cross-sectional areas of individual bubbles within a selected image were determined and then transformed into equivalent spherical radii. These data combined with an estimate of the imaging volume formed the basis of the bubble size distributions presented in Fig. 1.

The reference distribution for a laboratory plunging breaking wave from Deane and Stokes (2002) is in absolute units of bubbles $\mathrm{m}^{-3} \mu \mathrm{m}^{-1}$ radius increment, which is standard for the oceanographic literature. The distributions for sintered glass filters and plunging water were variable, depend-

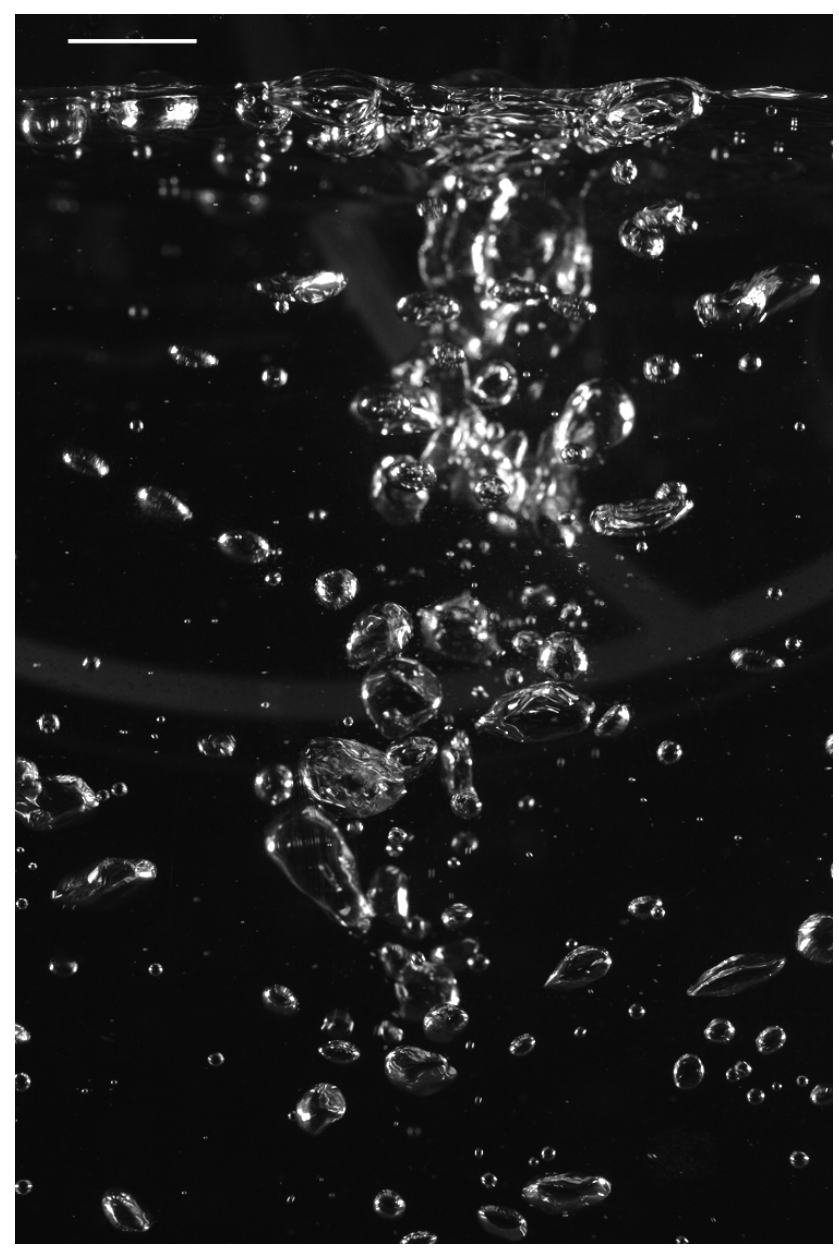

Figure 3. Side view of a partial bubble plume generated during miniMART operation. The white scale bar at top of image is $1 \mathrm{~cm}$. Bubbles both larger and smaller than the Hinze scale are present. The free-fall distance between the exit hole of the waterwheel and the water surface is approximately $10 \mathrm{~cm}$ (not seen in photograph).

ing on air flow, plunging sheet height and roughness, among other factors in the MART. To facilitate comparison with the breaking wave, the bubble size distributions for the sintered glass filters and plunging waterfall were first converted to probability density functions (PDFs) and then scaled by $5.6 \times 10^{6}$. The scaling factor was determined to be the value that brought the miniMART, MART and breaking wave distributions into agreement at a bubble radius of $\sim 1 \mathrm{~mm}$.

Both MART and miniMART systems approximate the bubble size distribution scaling laws found in breaking oceanic waves, including the production of bubbles larger than $a_{\mathrm{H}}$ (in this case, approximately $1.5 \mathrm{~mm}$ radius). However, the number of bubbles larger than $0.1 \mathrm{~mm}$ radius produced by miniMART is less than in MART by up to an order of magnitude. For bubbles smaller than approximately $0.1 \mathrm{~mm}$ radius there is a greater concentration in miniMART than in the original MART; this is attributed to the visible 
turbulent suspension of these bubbles in the smaller volume of miniMART and the buildup of greater concentration as plunging continues, whereas in the larger volume of the MART system these small bubbles advect away from the plunging jet and more readily degas at the water surface.

\subsection{Aerosol size distributions and residence time}

Particle size distributions (PSDs) were determined by a commercially available Scanning Mobility Particle Sizer (SMPS) (Wang and Flagan, 1990) and Aerodynamic Particle Sizer (APS) (Peters and Leith, 2003). The SMPS measures particle mobility diameter $\left(d_{\mathrm{m}}\right)$ by scanning the voltage across two electrodes within a differential mobility analyzer (DMA) column (TSI, Inc., Model 3080). Sampled particles are directed past a $0.058 \mathrm{~cm}$ impactor to remove particles too large for analysis and into the DMA column, which separates particles by electrical mobility. The range of particle sizes which can be analyzed with this method is dependent on the aerosol and sheath flow rates, which were set at 0.6 and 3.0 $\mathrm{L} \mathrm{min}^{-1}$, respectively, which corresponds to particle diameters of approximately $10-600 \mathrm{~nm}$. Particles selected in the DMA are injected into a condensation particle counter (TSI, Inc., Model 3010), which counts the particles corresponding to the sizes selected by the DMA. Reported size distributions are corrected for diffusive losses of particles using the SMPS processing software.

The APS (TSI Model 3321) determines the aerodynamic diameter $\left(d_{\mathrm{a}}\right)$ of particles in the 0.542 to $20 \mu \mathrm{m}$ range by measuring particle time of flight. Particles were sampled at 5.0 $\mathrm{L} \mathrm{min}^{-1}$ (1.0 and 4.0 $\mathrm{L} \mathrm{min}^{-1}$, aerosol and sheath flow rates, respectively). To determine $d_{\mathrm{a}}$, particles enter the inlet of the APS and pass between two separate paths of a continuous wave laser split with a beam splitter. From the transit time between the laser beams, the aerodynamic diameter can be determined.

For both the SMPS and APS analysis, particles were initially passed through silica gel diffusion dryers, where they were dried to an RH of $35 \pm 3 \%$. The $d_{\mathrm{m}}$ and $d_{\mathrm{a}}$ size distributions recorded were merged to obtain an estimate of the geometric physical diameter $\left(d_{\mathrm{p}}\right)$ size distribution across the size range of both instruments. For the purposes of merging, particles sized by the SMPS were assumed to be of a spherical geometry, which allows for the following relation:

$d_{\mathrm{m}}=d_{\mathrm{p}}$.

Particles sized by the APS were assigned an effective density, $\rho_{e f f}$, of $2.1 \mathrm{~g} \mathrm{~cm}^{-3}$, a value determined experimentally, which allows for conversion based on the following relation:

$d_{\mathrm{p}}=\frac{d_{\mathrm{a}}}{\sqrt{\frac{\rho_{\mathrm{eff}}}{\rho_{0}}}}$

with $\rho_{0}$ equal to unit density (i.e., $1 \mathrm{~g} \mathrm{~cm}^{-3}$ ). Both instruments had their resolution set to 32 bins per decade for consistency in merging. The SMPS tends to undercount particles at the high end of the distribution due to the cut-off from the particle impactor, while the APS can undercount particles at the low end due to poor scattering efficiency of the smallest particles. As a result, particle bins in the overlapping size region of the two methods were subsequently removed, excluding the largest and smallest bins of the SMPS and APS, respectively (Fig. 4a).

Particle sampling was conducted via a $10 \mathrm{~mm}$ internal diameter stainless steel tube passed through a sealed gland in the miniMART lid and positioned with its inlet above the bubble plume. The inlet was positioned at 2, 4, 8 and $15 \mathrm{~cm}$ above the water surface and additional samples were taken with a cone-shaped flared funnel ( $7 \mathrm{~cm}$ mouth diameter) attached to the end of the sampling tube and positioned approximately $1.5 \mathrm{~cm}$ from the water surface. The greatest number concentration of particles was collected when the inlet was positioned closest $(2 \mathrm{~cm})$ to the water surface and the number concentration decreased with increasing inlet height. This is most evident in the APS data, whereas the SMPS data showed light variation attributed to the noise in the sample signal due to the smaller number of particles counted by the CPC in each individual size bin during an SMPS scan. The addition of the cone to the inlet decreased the number of particles collected, particularly in the smaller size particles $(<2 \mu \mathrm{m})$ perhaps due to differential deposition on the cone walls.

During miniMART operation, carrier gas (either $\mathrm{N}_{2}$ or zero air) is supplied to the sealed tank at flow rates ranging between 1 and 10 slpm depending on instrument sampling requirements. The carrier gas flow, combined with particle deposition within the tank, determines the average lifetime of a particle in the system prior to sampling. The $e$-folding time with respect to mixing is set by the headspace volume $(\sim 10 \mathrm{~L})$ and the carrier gas flow rate. For the three flow rates studied here $(1.6,2.6$, and $3.6 \mathrm{slpm})$ the average particle lifetimes with respect to mixing are 5.6, 3.4, and $2.5 \mathrm{~min}$, respectively. To assess deposition within the tank, we arrest plunging and particle production and monitor the decay in the size-dependent number concentration. Size-dependent decay rates are shown in Fig. 5 as a function of carrier gas flow. The deviation in the decay from that determined from mixing alone is a low bound on particle deposition within the tank. Actual deposition rates are likely faster when the water wheel is turning and the jet is plunging. As shown in Fig. 5, particle deposition is strongly size dependent, where the observed particle lifetimes span between approximately 1 and $4 \mathrm{~min}$ for a carrier gas flow rate of $1.6 \mathrm{slpm}$.

In a separate experiment, aerosol PSDs from a separate miniMART were characterized using a Scanning Electrical Mobility Sizer (SEMS) instrument (BMI Model 2002). The SEMS is similar to the SMPS in that particles are characterized according to their electrical mobility diameters. However, the SEMS DMA design allows for measurement to larger mobility diameters. Here, the range of measured diameters was 10.3 to $946 \mathrm{~nm}$. The SEMS was oper- 


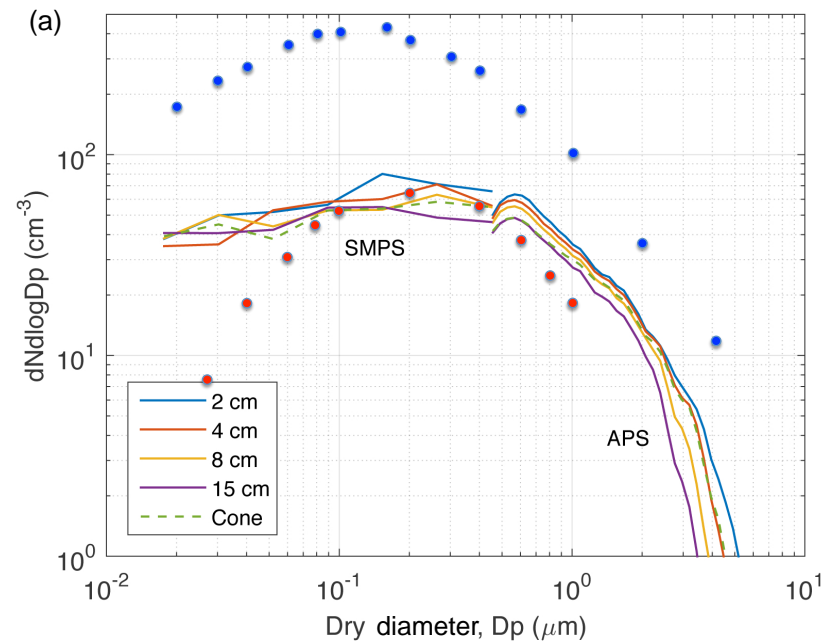

(b)

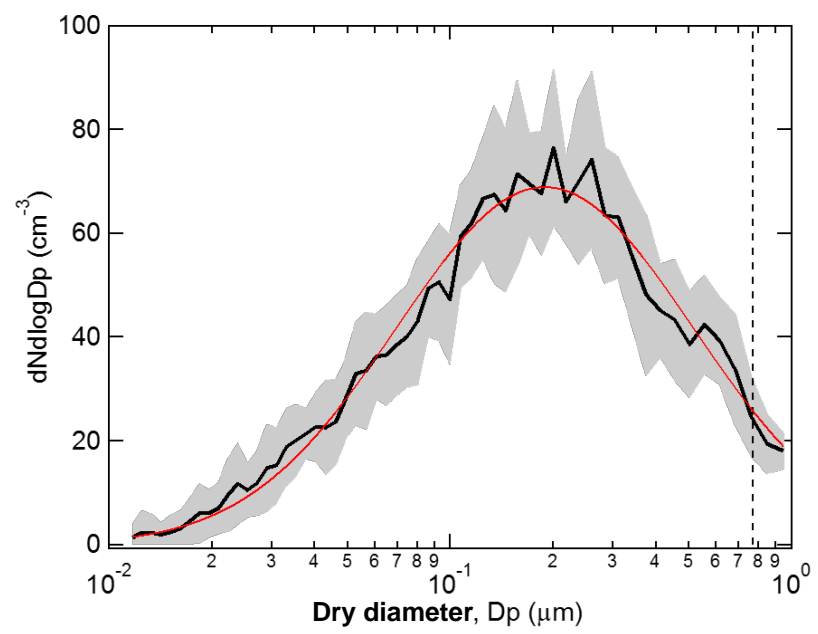

Figure 4. (a) Number concentrations of sea spray aerosol (SSA) generated by miniMART. The SSA particle diameter was measured at $35 \pm 3 \%$ relative humidity and converted to dry diameter. SSA concentrations were measured using a TSI Scanning Mobility Particle Sizer (SMPS) for SSA $<\sim 500 \mathrm{~nm}$ and a TSI Aerodynamic Particle Sizer (APS) for SSA $>\sim 600 \mathrm{~nm}$. Concentrations are shown for SSA collected with the miniMART sample tube located within $2,4,8$ and $15 \mathrm{~cm}$ of the water surface as well as with a coneshaped flared funnel $(7 \mathrm{~cm}$ mouth diameter) positioned approximately $1.5 \mathrm{~cm}$ from the water surface. Red filled circles show number concentrations of SSA diameter from miniMART filled with a $3.5 \% \mathrm{NaCl}$ solution using a SEMS (see Fig. 4b). Blue filled circles show an example of a SSA number concentration in unfiltered, natural seawater in a MART system from Collins et al. (2014). (b) The average number-weighted size distribution (black line) and the $\pm 1 \sigma$ band (gray region) measured by the SEMS. The red curve is a fit to the data assuming a single log-normal distribution (median diameter $=189 \mathrm{~nm}$, width $=2.32$ ). The vertical dashed line at $770 \mathrm{~nm}$ indicates the $50 \%$ mobility-equivalent cutoff diameter for the SEMS impactor.
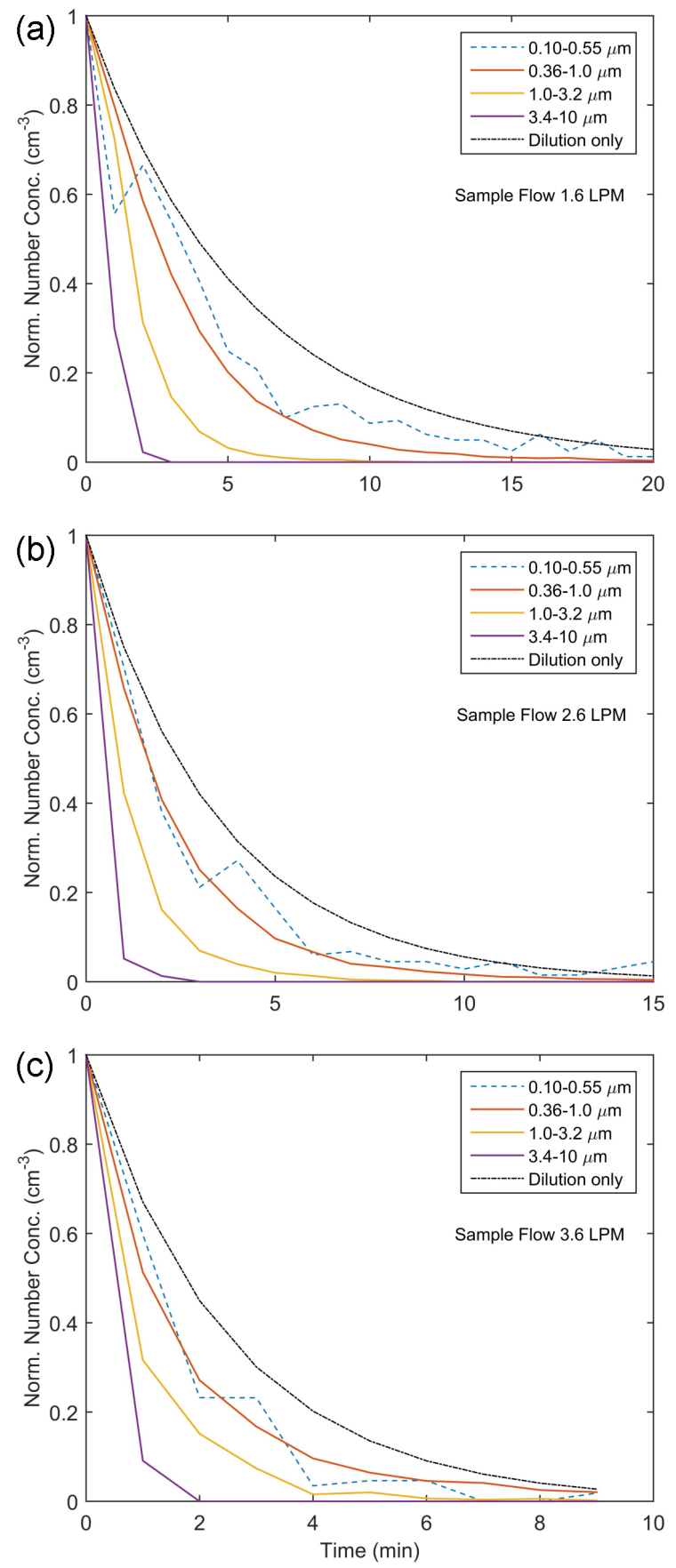

Figure 5. Normalized size-dependent decay rates in particle number concentration $\left(\mathrm{cm}^{-3}\right)$ for three different dilution air flow conditions: 1.6 standard $\mathrm{L} \mathrm{min}^{-1}$ (a), $2.6 \mathrm{slpm}$ (b), and $3.6 \mathrm{slpm}$ (c). Particle number concentrations are shown for size classes $0.1-$ $0.55 \mu \mathrm{m}$ (from the SMPS), 0.56-1.0, 1.0-3.2, and 3.4-10 $\mu \mathrm{m}$ (from the APS). The associated $e$-folding lifetimes $(\tau)$ for each flow condition and size regime, and the expected decay rates from dilution alone are discussed in the text. 
ated with an impactor with a $50 \%$ cutoff $d_{\mathrm{a}} \sim 1,150 \mathrm{~nm}$ at the $0.36 \mathrm{~L} \mathrm{~min}^{-1}$ sample flow rate, which corresponds to a $d_{\mathrm{m}} \sim 770 \mathrm{~nm}$, assuming $\rho_{\text {eff }}=2.1 \mathrm{~g} \mathrm{~cm}^{3}$. The effective averaging time at each size, which determines the particle counting statistics, was either 5 or $10 \mathrm{~s}$; the results from both were similar so only the $10 \mathrm{~s}$ results are presented here. The measured size distributions were corrected for diffusive losses within the SEMS assuming that the effective length of the SEMS (consisting of the DMA column, ${ }^{210}$ Po bipolar diffusion charger, $30 \mathrm{~cm}$. Nafion dryer and other tubing) was $11 \mathrm{~m}$ (Wiedensohler et al., 2012). In the experiment using the SEMS, the flow rate of carrier gas through miniMART was $0.86 \mathrm{slpm}$, which is lower than that in the SMPS + APS experiments discussed above. Particles were sampled from miniMART through a silica gel diffusion dryer $(\mathrm{RH}<20 \%)$ and then the flow was split to the SEMS $\left(0.36 \mathrm{~L} \mathrm{~min}^{-1}\right)$ and to the atmosphere $\left(0.5 \mathrm{~L} \mathrm{~min}^{-1}\right)$. The tank was filled to $13 \mathrm{~cm}$ from the bottom of the tank with a $3.5 \% \mathrm{NaCl}$ solution in Milli-Q water. The $9.5 \mathrm{~mm}$ OD (7.5 mm ID) stainless steel sampling tube was positioned $2 \mathrm{~cm}$ above the water surface and the tube inlet was cut at $45^{\circ}$ to prevent clogging with water. A total of 16 sequential PSD scans were measured after the system reached steady state. The average of these 16 scans is shown in Fig. 4b. The mode peak of the SEMS PSD was around $200 \mathrm{~nm}$, similar to other results and similar to that for MART in Stokes et al. (2013).

Although the average PSD from the miniMART measured using the SEMS peaks in the same general size range as the SMPS, there are distinct differences. In particular, the SEMS measurements indicate a more substantial falloff in concentration towards smaller sizes than do the SMPS measurements. The SEMS and APS measurements are in reasonable agreement in terms of the shape of the distribution at larger sizes. The greater apparent falloff in the SEMS PSD at small sizes could indicate that the internal diffusion correction applied was too small (or too large in the SMPS) or that diffusional losses between the miniMART and sizing instrumentation were larger in the SEMS experiments, perhaps due to the smaller flow rate. Future experiments in which the SMPS and SEMS are simultaneously used to characterize PSDs from the miniMART will help to resolve this discrepancy. Regardless, the generally good correspondence of the PSDs from miniMART with PSDs of nascent SSA from breaking waves (Prather et al., 2013) and the MART (Stokes et al., 2013) suggests that the miniMART can operate as a suitable SSA mimic.

\section{Comparison of miniMART to other generation methods}

As noted by Sellegri et al. (2006) and Fuentes et al. (2010), a plunging water jet best replicates the bubble plumes generated by an oceanic whitecap. Comparison of the bubble plume formed by the miniMART system to those gener- ated by air flow through sintered glass filters and to those formed in oceanic waves and within the larger MART system (Fig. 1) illustrates that a plunging sheet of water forms a broader spectrum of bubble sizes than the sintered glass filters tested, including bubbles larger than about $1 \mathrm{~mm}$ in radius. The slopes of the bubble density size spectrum in the miniMART plumes are very similar to the slopes of oceanic and laboratory breaking waves at sizes smaller and larger than the Hinze scale $\left(a_{\mathrm{H}}\right)$ as well as to the larger MART system. For comparison, the bubble plumes generated by sintered filters have a much narrower size spectrum and tend not to include bubbles larger than about $800 \mu \mathrm{m}$ radius.

The bubble plumes generated by the plunging jet within miniMART penetrate approximately $15 \mathrm{~cm}$ beneath the water surface, which is not as deep as the plumes generated by MART or by spilling breakers in the lab and ocean (Deane and Stokes, 2002). However, the intermittent cycling of the plunging jet in miniMART system allows the bubble plume and resulting surface foam patch to evolve over time, creating a bubble and aerosol source that seems to be a fairly close match to the decaying patches of foam produced by whitecaps than that provided by constant, stationary jets. The importance of decaying foams (as opposed to pseudo-steadystate foams, for which decay rates are matched by bubble entrainment rates) remains an open question, but may be important. For example, the jet drop production mechanism may be somewhat suppressed in steady-state foams if they are more than a single bubble layer thick because the top layer of foam film can absorb jet drop aerosols produced at the air-water interface (Collins et al., 2014). Foams allowed to decay, even if they are initially three-dimensional in structure, will eventually devolve into two-dimensional rafts of bubbles which will not suppress jet drops.

The particle number distribution measured using the miniMART and MART system are similar to the size distribution obtained by Fuentes et al. (2010). It is notable that the particle number distributions obtained using the miniMART (Fig. 4) and MART systems have less pronounced characteristics of sub-100 nm modes, with the dominant number distribution mode around $200 \mathrm{~nm}$, broadly tailing off to both larger and smaller sizes (see details for MART in Fig. 5, of Stokes et al., 2013). This result is consistent with the broad bubble size spectrum and accurate representation of bubbles larger than $1 \mathrm{~mm}$ that is achieved by both miniMART and the larger MART system. Particle number distributions measured in both are in strong agreement with those previously measured from breaking waves in the Scripps Institution of Oceanography Hydraulics Laboratory (Prather et al., 2013). These measurements highlight the importance of an accurate representation of bubble formation processes in the creation of sea-spray aerosol in the laboratory. The primary difference between the miniMART and MART systems is the lower particle flux generated by the smaller and less energetic plunging jet in miniMART. For example, the submicron- and supermicron-sized particle number, surface 

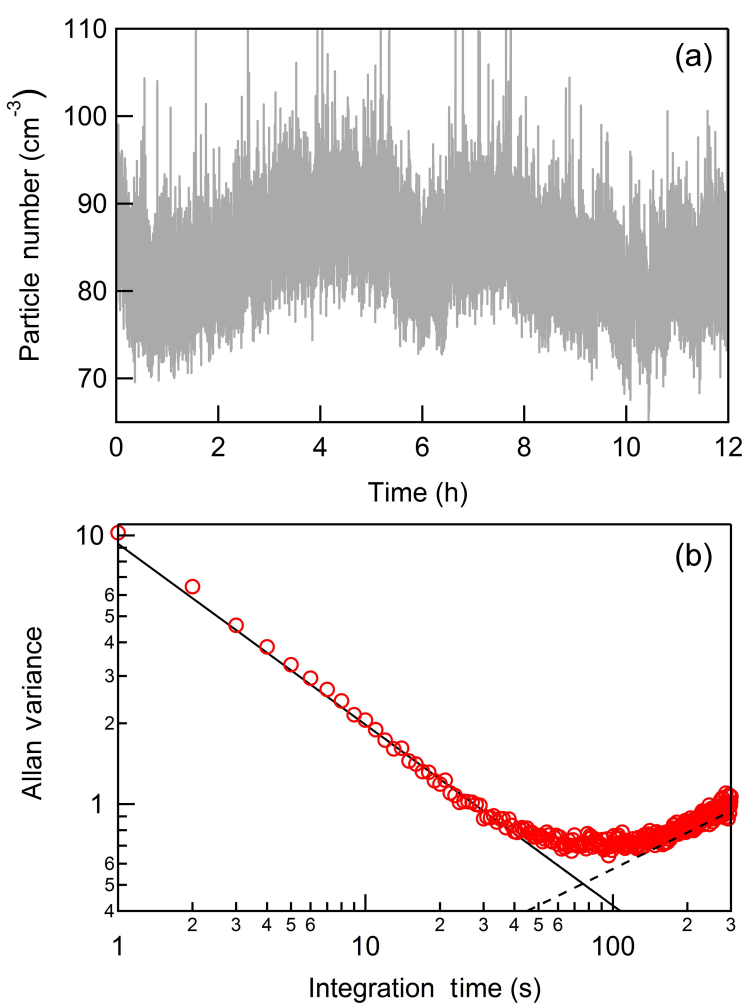

Figure 6. (a) Twelve-hour time series of $1 \mathrm{~Hz}$ CPC measurements from a miniMART containing a $500 \mathrm{mM}$ solution of $\mathrm{NaCl}$. (b) $\mathrm{Al}-$ lan variance plot, calculated using the data shown in the top panel. At long integration times, flow controller drift and temperature fluctuations likely contribute to source fluctuations.

area and mass concentration in MART were approximately 5000 and $345 \mathrm{~cm}^{-3}, 1260$ and $2800 \mu^{2} \mathrm{~cm}^{-3}$, and 200 and $1735 \mathrm{\mu g} \mathrm{m}^{-3}$ (assuming a particle density of $1.8 \mathrm{~g} \mathrm{~cm}^{-3}$ ), respectively, at a flow rate of $3 \mathrm{slpm}$ (Stokes et al., 2013). While for the miniMART, these numbers were approximately 90 and $60 \mathrm{~cm}^{-3}, 160$ and $900 \mu \mathrm{m}^{2} \mathrm{~cm}^{-3}, 50$ and $125 \mu \mathrm{g} \mathrm{m}^{-3}$, respectively, at a flow rate of $2.6 \mathrm{slpm}$, necessitating longer sample integration times for some instrumentation, like the SMPS.

The reduced particle number concentrations in miniMART, in comparison to MART, can present a challenge for particle instrumentation (e.g., size resolved cloud condensation nuclei measurements). For instruments where the noise is dominated by counting statistics, signal-to-noise ratios can theoretically be improved by signal averaging. An important consideration, with respect to miniMART, is the stability of the particle source and air delivery as a function of instrument integration time. Allan variance can be used to determine the timescale for which signal averaging in the miniMART will no longer improve instrument signalto-noise ratio (Werle et al., 1993). Twelve continuous hours of $1 \mathrm{~s}$ CPC measurements from a miniMART containing a $500 \mathrm{mM} \mathrm{NaCl}$ solution are shown in Fig. 6a. The Allan vari-
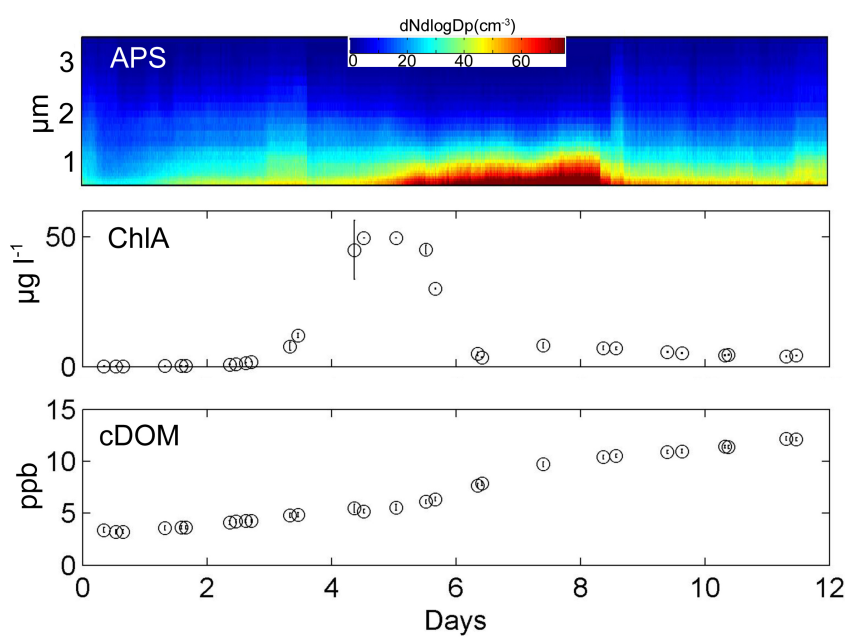

Figure 7. Example miniMART experimental time series for a 12day incubation of nutrient-spiked, filtered seawater. The top panel shows continuous APS-determined aerosol size number concentration for particles from 0.6 to $3.5 \mu \mathrm{m}$ dry diameter. The center panel shows chlorophyll $a$ concentration $\left(\mu \mathrm{g} \mathrm{L}^{-1}\right)$ and the lower panel shows colored dissolved organic matter (cDOM, ppb) from the miniMART bulk water during the incubation. Vertical bars indicate \pm 1 SD.

ance was calculated from these data and are shown in Fig. 6b. The analysis indicates that improvement in signal-to-noise ratio will be achieved for averaging times up to $100 \mathrm{~s}$, after which further signal averaging will result in a decrease in the signal-to-noise ratio. Further work is required to establish the experimental factors that control this optimum averaging time.

A primary motivation for the fabrication of miniMART was to create an SSA analogue that allowed continuous aerosol sampling during the growth and culturing of planktonic cells. Figure 7 shows data collected during a 12-day miniMART incubation of sand-filtered seawater spiked with nutrients at $0 \mathrm{~h}$. Aerosols were sampled continuously with an APS from the tank headspace with a carrier gas flow of $1.9 \mathrm{slpm}$. In addition, chlorophyll $a$ concentrations and dissolved organic matter (cDOM) concentrations were measured at semi-regular intervals from miniMART water drawn via a peristaltic pump into a closed-loop analysis system (Wetlabs Ecotriplet), and then returned, to prevent the loss of water from the system during sampling. Exponential growth of microorganisms (primarily diatoms) peaks around day 4 with an increase in the number density of aerosols increasing after the initial bloom and while the chlorophyll $a$ concentrations drop, associated with the death of the diatoms and rapid increase in the number of bacteria and viruses which cause cellular lysis and the increase in dissolved organics. Similar preliminary experiments have been run showing multiple microbial blooms and crashes during miniMART incubations for weeks in duration. Understanding the factors that drive 
the variability in the produced SSA particle concentrations that is evident in Fig. 7 is the subject of future work.

\section{Conclusions}

In order to mimic the SSA created by oceanic whitecaps any surrogate system must reproduce the complex two-phase flows, bubble plumes and surface foam patches naturally generated during a breaking wave. These conditions can be accurately replicated in large seawater breaking wave channels. However, these facilities are not readily available, and due to their extremely large volume it is extremely difficult to enclose them for high fidelity aerosol sampling and difficult to carefully control the environmental conditions to allow replicate experiments. Sintered glass filters (frits) bubbling air in an enclosed container produce controllable plumes; however, the bubbles produced are constrained to a narrow size spectrum much more narrow than that observed in a natural whitecap.

When using plunging water to create bubble plumes, it is important that the falling sheet or jet has the appropriate scale of surface roughness before impacting the water surface in order to create the correctly sized voids along the air-water interface (Zhu et al., 2000). The larger voids are important for producing the correct plume bubble size distribution that includes bubbles larger than the Hinze scale. Stationary, narrow cross-sectional area and high velocity jets may not entrain large bubbles characteristic of whitecaps without the correct scale of disturbances on their surface before impacting the water.

It is apparently important that any bubble plume surrogate provide the correct intermittency in production. Natural whitecap plumes and the resulting surface foam evolve over a timescale of seconds to tens of seconds, whereas continuous water jets impacting the surface at a fixed location create subsurface flow fields unlike breaking events. Continuous sparging of air through frits and nozzles or air entrainment by continuous jets can also create three-dimensional surface foams that do not evolve and dissipate like those within oceanic whitecaps, and these can bias physical and chemical attributes of the aerosols created when the bubbles rupture (Prather et al., 2013; Collins et al., 2014).

The bubble plume and resulting aerosol particle size distribution generated within the miniMART and MART systems resembles that generated from breaking waves within the SIO glass-walled wave channel. Confining the bubble generation to a smaller headspace air volume $(\angle 50 \mathrm{~L}$ in the MART and $\sim 10 \mathrm{~L}$ in miniMART) as compared to the wave channel permits a significant increase in particle number concentrations (from 100 , to $>5000$, to approximately 500 particles $\mathrm{cm}^{-3}$, for the wave channel, MART and miniMART, respectively). As a result, the surrogate MART and miniMART systems enable a wide variety of measurements (e.g., size resolved hygroscopicity and heterogeneous reactivity) that are not feasible at the low number concentrations produced in the wave channel and allow for the controlled study of the chemistry and physics of marine bubbles, foam and aerosols. In these systems, experiments are more easily repeatable even while environmental variables, like the seawater and atmospheric chemistry and the physical forcing mechanisms controlling the plume dynamics, are manipulated. The pumpfree action of miniMART allows the long-term growth and monitoring of delicate planktonic cell cultures while continuously producing aerosols for study, with the caveat that the flux of particles is less than in the larger MART system, a factor which must be considered in any particle sampling protocols. For experiments requiring the generation and collection of large numbers of aerosol particles that do not require the continuous presence of delicate organisms in the water, the original MART system remains the breaking wave surrogate of choice.

\section{Data availability}

All data sets used in this research can be provided through contact with the corresponding author. In addition, access can be acquired via contact with the NSF Center for Aerosol Impacts and the Environment (CAICE) at UCSD (http://caice. ucsd.edu/index.php/research/tools/).

Acknowledgements. This research was conducted within the Center for Aerosol Impacts on Climate and the Environment (CAICE), a National Science Foundation Center for Chemical Innovation (CHE-1305427).

Edited by: H. Herrmann

Reviewed by: two anonymous referees

\section{References}

Bezzabotnov, V. S., Bortkovskii, R. S., and Timanovskii, D. F.: On the structure of the two-phase medium generated at windwave breaking, Izvestiya Akedemii Nauk SSR, Fizika Atmosfery I Okeana, 22, 1186-1193, 1986.

Bowyer, P. A.: Video measurements of near-surface bubble spectra, J. Geophys. Res., 106, 14179-14190, 2001.

Braban, C. F, Adams, J. W., Rodriguez, D., Cox, R. E., Crowley, J. N., and Schuster, G.: Heterogeneous reactions of HOI, ICl and IBr on sea salt and sea salt proxies, Phys. Chem. Chem. Phys., 9, 3136-3148, 2007.

Cipriano, R. J. and Blanchard, D.: Bubble and Aerosol Spectra Produced by a Laboratory "Breaking Wave", J. Geophys. Res., 86, 8085-8092, 1981.

Cloke, J., McKay, W. A., and Liss, P. S.: Laboratory investigations into the effect of marine organic material on the sea-salt aerosol generated by bubble bursting, Mar. Chem., 34, 77-95, 1991.

Collins, D. B., Zhao, D. F., Ruppel, M. J., Laskina, O., Grandquist, J. R., Modini, R. L., Stokes, M. D., Russell, L. M., Bertram, 
T. H., Grassian, V. H., Deane, G. B., and Prather, K. A.: Direct aerosol chemical composition measurements to evaluate the physicochemical differences between controlled sea spray aerosol generation schemes, Atmos. Meas. Tech., 7, 3667-3683, doi:10.5194/amt-7-3667-2014, 2014.

Deane, G. B. and Stokes, M. D.: Scale dependence in bubble creation mechanisms in breaking waves, Nature, 418, 839-844, 2002.

Deane, G. B. and Stokes, M. D.: Model calculations of the underwater noise of breaking waves and comparison with experiment, J. Acoust. Soc. Am., 127, 3394-3410, 2010.

de Leeuw, G. and Cohen, L.: Bubble size distributions on the North Atlantic and North Sea, Gas Transfer at Water Surfaces, Geoph. Monog. Series, 127, 271-277, 2002.

de Leeuw, G. and Leifeer, I.: Bubbles outside the plume during the LUMINY wind-wave experiment, Gas Transfer at Water Surfaces, Geoph. Monog. Series, 127, 295-301, 2002.

Facchini, M. C., Rinaldi, M., Decesari, S., Carbone, C., Finessi, E., Mircea, M., Fuzzi, S., Ceburnis, D., Flanagan, R., Nilsson, E. D, de Leeuw, G., Martino, M., Woeltjen, J., and O'Dowd, C. D.: Primary submicron marine aerosol dominated by insoluble organic colloids and aggregates, Geophys. Res. Lett., 35, L17814, doi:10.1029/2008GL034210, 2008.

Fuentes, E., Coe, H., Green, D., de Leeuw, G., and McFiggans, G.: Laboratory-generated primary marine aerosol via bubblebursting and atomization, Atmos. Meas. Tech., 3, 141-162, doi:10.5194/amt-3-141-2010, 2010.

Herrero, S.: Bear attacks their causes and avoidance, Hurtig, McClelland \& Stewart Co. Publ. Toronto, 304 pp., ISBN-13: 978$1585745579,1985$.

Hultin, K. A. H., Nilsson, E. D., Krejci, R., Martensson, E. M., Hagstrom, A., and de Leeuw, G.: In situ laboratory sea spray production during the MAP 2006 cruise on the North East Atlantic, J. Geophys. Res., 115, D06201, doi:10.1029/2009JD012522, 2010.

Keene, W. C., Maring, H. , Maben, J. R., Kieber, D. J., Pszenny, A. A. P., Dahl, E. E., Izaguirre, M. A., Davis, A. J., Long, M. S., Zhou, X., Smoydzin, L., and Sander, R.: Chemical and physical characteristics of nascent aerosols produced by bursting bubbles at a model air-sea interface, J. Geophys. Res., 112, D21202, doi:10.1029/2007JD008464, 2007.

Lamarre, E. and Melville, W. K.: Void-fraction measurements and sound-speed fields in bubble plumes generated by breaking waves. J. Acous. Soc. Am., 95, 1317-1328, 1994.

Lee, C., Sultana, C. M., Collins, D. B., Santander, M. V., Axson, J. L., Malfatti, F., Cornwell, G. C., Grandquist, J. R., Deane, G. B., Stokes, M. D., and Azam, F.: Advancing Model Systems for Fundamental Laboratory Studies of Sea Spray Aerosol Using the Microbial Loop, J. Phys. Chem. A, 119, 8860-8870, 2015.

Leighton, T. G., Phelps, A. D., and Ramble, G. D.: Acoustic bubble sizing: from the laboratory to the surf zone trials, Acoustics Bull., 21, 5-12, 1996.

Leifer, I. and de Leeuw, G.: Bubble measurments in breaking-wave generated bubble plumes during the LUMINY wind-wave experiment, Gas Transfer at Water Surfaces, Geoph. Monog. Series, 127, 303-309, 2002.

Leifer, I. and de Leeuw, G.: Bubbles generated from windsteepened breaking waves: 1 . bubble plume bubbles, J. Geophys. Res. 111, C06020, doi:10.1029/2004JC002676, 2006.
Lewis, E. R. and Schwartz, S. E.: Sea Salt Aerosol Production: Mechanisms, Methods, Measurements, and Models: A Critical Review, American Geophysical Union, Washington, DC, 413 pp., ISBN-13: 978-0-87590-417-7, 2004.

Loewen, M. R., O’Dor, M. A., and Skafel, M. G.: Laboratory measurements of bubble size distributions beneath breaking waves, in, Air-Sea Gas Transfer, Third International Symposium on AirWater gas transfer, edited by: Jahne, B. and Monahan E. C., AEON Verlag \& Studio, Germany, 337-345, 1995.

Martensson, E. M. , Nilsson, E. D., Cohen, L. H., and de Leeuw, G.: Laboratory simulations and parameterization of the primary marine aerosol production, J. Geophys. Res., 108, 4297, doi:10.1029/2002JD002263, 2003.

McNeill, V. F., Patterson, J., Wolfe, G. M., and Thornton, J. A.: The effect of varying levels of surfactant on the reactive uptake of $\mathrm{N}_{2} \mathrm{O}_{5}$ to aqueous aerosol, Atmos. Chem. Phys., 6, 1635-1644, doi:10.5194/acp-6-1635-2006, 2006.

Melville, W. K.: The role of surface-wave breaking in airsea interaction, Annu. Rev. Fluid Mech., 28, 279-321, doi:10.1146/annurev.fl.28.010196.001431, 1996.

Monahan, E. C. and Zeitlow, C. R.: Laboratory comparisons of fresh-water and salt-water whitecaps, J. Geophys. Res., 74, 6961-6966, 1969.

Niedermeier, D., Wex, H., Voigtländer, J., Stratmann, F., Brüggemann, E., Kiselev, A., Henk, H., and Heintzenberg, J.: LACISmeasurements and parameterization of sea-salt particle hygroscopic growth and activation, Atmos. Chem. Phys., 8, 579-590, doi:10.5194/acp-8-579-2008, 2008.

Peters, T. M. and Leith, D.: Concentration measurement and counting efficiency of the aerodynamic particle sizer 3321, J. Aerosol Sci., 34, 627-634, 2003.

Prather, K. A., Bertram, T. H., Grassian, V. H., Deane, G. B., Stokes, M. D., DeMott, P. J., Aluwihare, L. I., Palenik, B. P., Azam, F., Seinfeld, J. H., and Moffet, R.C.: Bringing the ocean into the laboratory to probe the chemical complexity of sea spray aerosol, P. Natl. Acad. Sci., 110, 7550-7555, 2013.

Rapp, R. J. and Melville, W. K.: Laboratory measurements of deepwater breaking waves, Philos. T. Roy. Soc. A, 331, 735-800, 1990.

Riziq, A., Erlick, C., Dinar, E., and Rudich, Y.: Optical properties of absorbing and non-absorbing aerosols retrieved by cavity ring down (CRD) spectroscopy, Atmos. Chem. Phys., 7, 1523-1536, doi:10.5194/acp-7-1523-2007, 2007.

Saul, T. D., Tolocka, M. P., and Johnston, M. V.: Reactive uptake of nitric acid onto sodium chloride aerosols across a wide range of relative humidities, J. Phys. Chem. A, 110, 7614-7620, 2006.

Sellegri, K., O’Dowd, C. D., Yoon, Y. J., Jennings, S. G., and de Leeuw, G.: Surfactants and submicron sea spray generation, J. Geophys. Res., 111, D22215, doi:10.1029/2005JD006658, 2006.

Solomon, S., Qin, D., Manning, M., Chen, Z., Marquis, M., Averyt, K., Tignor, M., Miller, H. (Eds.): IPCC, 2007: Climate Change 2007: The Physical Science Basis. Contribution of Working Group I to the Fourth Assessment, Cambridge University Press, 2007.

Stokes, M. D., Deane, G., Vagle, S., and Farmer, D.: Measurements of large bubbles in open-ocean whitecaps, Gas Transfer at Water Surfaces, Geoph. Monog. Series, 127, 279-284, 2002.

Stokes, M. D., Deane, G. B., Prather, K., Bertram, T. H., Ruppel, M. J., Ryder, O. S., Brady, J. M., and Zhao, D.: A Marine Aerosol 
Reference Tank system as a breaking wave analogue for the production of foam and sea-spray aerosols, Atmos. Meas. Tech., 6, 1085-1094, doi:10.5194/amt-6-1085-2013, 2013.

Svenningsson, B., Rissler, J., Swietlicki, E., Mircea, M., Bilde, M., Facchini, M. C., Decesari, S., Fuzzi, S., Zhou, J., Mønster, J., and Rosenørn, T.: Hygroscopic growth and critical supersaturations for mixed aerosol particles of inorganic and organic compounds of atmospheric relevance, Atmos. Chem. Phys., 6, 1937-1952, doi:10.5194/acp-6-1937-2006, 2006.

Taketani, F., Kanaya, Y., and Akimoto, H.: Heterogeneous loss of $\mathrm{HO}_{2}$ by $\mathrm{KCl}$, synthetic sea salt, and natural seawater aerosol particles, Atmos. Environ., 43, 1660-1665, 2009.

Tseng, R.-S., Viechnicki, J., Skop, R., and Brown, J.: Sea-to-air transfer of surface-active organic compounds by bursting bubbles, J. Geophys. Res., 97, 5201-5206, 1992.

Tyree, C. A., Hellion, V. M., Alexandrova, O. A., and Allen, J. O.: Foam droplets generated from natural and artificial seawaters, J. Geophys. Res., 112, D12204, doi:10.1029/2006JD007729, 2007.

Wallace, G. T. and Duce, R. A.: Transport of particulate organic matter by bubbles in marine waters, Limnol. Oceanogr.-Meth., 23, 1155-1167, 1978.

Wang, S. C. and Flagan, R. C.: Scanning electrical mobility spectrometer, Aerosol Sci. Tech., 13, 230-240, 1990.

Werle, P., Mucke, R., and Slemr, F.: The Limits of Signal Averaging in Atmospheric Trace-Gas Monitoring by Tunable Diode-Laser Absorption-Spectroscopy (TDLAS), Appl. Phys. B Photo., 57, 131-139, 1993.
Wiedensohler, A., Birmili, W., Nowak, A., Sonntag, A., Weinhold, K., Merkel, M., Wehner, B., Tuch, T., Pfeifer, S., Fiebig, M., Fjäraa, A. M., Asmi, E., Sellegri, K., Depuy, R., Venzac, H., Villani, P., Laj, P., Aalto, P., Ogren, J. A., Swietlicki, E., Williams, P., Roldin, P., Quincey, P., Hüglin, C., Fierz-Schmidhauser, R., Gysel, M., Weingartner, E., Riccobono, F., Santos, S., Grüning, C., Faloon, K., Beddows, D., Harrison, R., Monahan, C., Jennings, S. G., O’Dowd, C. D., Marinoni, A., Horn, H.-G., Keck, L., Jiang, J., Scheckman, J., McMurry, P. H., Deng, Z., Zhao, C. S., Moerman, M., Henzing, B., de Leeuw, G., Löschau, G., and Bastian, S.: Mobility particle size spectrometers: harmonization of technical standards and data structure to facilitate high quality long-term observations of atmospheric particle number size distributions, Atmos. Meas. Tech., 5, 657-685, doi:10.5194/amt5-657-2012, 2012.

Wise, M. E., Freney, E. J., Tyree, C. A., Allen, J. O., Martin, S. T., Russel, L. M., and Buseck, P. R.: Hygroscopic behaviour and liquid-layer composition of aerosol particles generated from natural and artificial seawater, J. Geophys. Res., 114, D03201, doi:10.1029/2008JA013848, 2009.

Woodcock, A. H.: Salt nuclei in marine air as a function of altitude and wind force, J. Meteorol., 10, 362-371, 1953.

Zhu, Y., Oguz, H. N., and Prosperetti, A.: On the mechanism of air entrainment by liquid jets at a free surface, J. Fluid Mech., 404, 151-177, 2000. 